Pollock, M. R. (1953). J. gen. Microbiol., 8, 186-197.

\title{
Penicillinase Adaptation and Fixation of Penicillin Sulphur by Bacillus cereus Spores
}

\author{
By M. R. POLLOCK \\ National Institute for Medical Research, Mill Hill, London, N.W. 7 \\ With a Note by C. J. Perret on the Biosynthesis and Isolation of \\ ${ }^{35}$ S-labelled Benzylpenicillin
}

\begin{abstract}
SUMMARY: In contrast to vegetative cells, Bacillus cereus spores do not react to treatment with penicillin by increased production of penicillinase when subsequently grown in a penicillin-free medium. Neither do spores show specific fixation of penicillin sulphur, with maximum absorption at $1.0 \mathrm{unit} / \mathrm{ml}$., which is characteristic of vegetative cells. However, treatment of vegetative cells with penicillin shortly before or during sporulation leads to the formation of 'adapted' spores able to form penicillinase up to 10 times more rapidly than untreated spores when subsequently germinated and grown in a penicillin-free medium; and specific uptake of penicillin $S$ on spore material occurs after mechanical disruption of the spore-wall. It is concluded that the fully mature and undamaged spore-casing is impermeable to penicillin.
\end{abstract}

Suspensions of vegetative cells of Bacillus cereus respond specifically to treatment with penicillin by rapidly producing penicillinase when subsequently grown in a penicillin-free medium (Pollock, 1950). The rate of penicillinaseformation is determined by the concentration of penicillin used, with a maximum at about $1 \cdot 0 \mathrm{unit} / \mathrm{ml} .\left(1 \cdot 7 \times 10^{-6} \mathrm{M}\right)$, and is proportional to the specific uptake of penicillin sulphur by the cells-as followed by the use of ${ }^{35} \mathrm{~S}$-labelled penicillin (Pollock \& Perret, 1951). Suspensions of spores, however, show no such response to penicillin when treated under similar conditions. Their rate of penicillinase formation is identical with the 'basal' rate shown by untreated spores; and their fixation of penicillin $S$ is of the 'non-specific' type, without the disproportionately high uptake at concentrations below 1 unit/ml, characteristic of vegetative cells. The work reported here was undertaken in an attempt to find an explanation of these differences.

\section{METHODS}

Medium. $10 \mathrm{~g}$. Evans peptone, $3 \mathrm{~g}$. Lemco and $2 \mathrm{~g}$. of $\mathrm{NaCl}$ were dissolved in 1 l. of water. The $\mathrm{pH}$ value was adjusted to $7 \cdot 6$ and the medium steamed for $30 \mathrm{~min}$. and filtered through paper to clarify. The $\mathrm{pH}$ value was then readjusted to $\mathbf{7 \cdot 0}$ and the medium autoclaved at $10 \mathrm{lb}$. for $20 \mathrm{~min}$. 'Sporulation' $(S)$ broth prepared in this way will allow $95 \%$ of $B$. cereus cells to undergo sporulation after $16 \mathrm{hr}$. growth from a suitable inoculum. If, however, the so-called 'phosphates' are removed-for instance by adjusting the $\mathrm{pH}$ value too high before steaming, and filtering off the resultant precipitate-sporulation will be almost completely prevented. 
Inoculum. One drop of various dilutions of a standard suspension of B. cereus NRRL 569 spores, having a viable count of $3 \times 10^{8} / \mathrm{ml}$., into 50 or $100 \mathrm{ml}$. of medium.

Vegetative cell suspensions. A $16 \mathrm{hr}$. culture incubated on a shaker at $35^{\circ}$, after inoculation with one drop of $10^{-6}$ dilution of standard spore suspension into $100 \mathrm{ml}$. of medium, was centrifuged, the cells washed once and made up to standard opacity by reference to an opacity/dry weight curve.

Spore suspensions. Cultures similar to that used for preparation of vegetative cells were allowed to remain shaking at $35^{\circ}$ for $40 \mathrm{hr}$., by which time most of the vegetative cell material had lysed. The spores were then centrifuged and washed once. They were resuspended in water and heated at $60^{\circ}$ for $1 \mathrm{hr}$., centrifuged down again, washed three times and finally resuspended to standard opacity. This gave a fairly homogeneous suspension of clean spores more or less free from vegetative cell debris.

Penicillinase production was followed aerobically at $35^{\circ}$ in $S$ medium containing $1 \%(\mathrm{w} / \mathrm{v})$ gelatin, samples being removed into $0.00084 \mathrm{M}$-oxine and assayed manometrically, all details being exactly as previously described (Pollock, 1950). Results are expressed as $\mu \mathrm{l}$. $\mathrm{CO}_{2}$ released (by the penicilloic acid) from a bicarbonate buffer at $\mathrm{pH} 7.0$ and $30^{\circ}$ by $1 \mathrm{ml}$. in $1 \mathrm{hr}$.

Radioactive benzylpenicillin labelled with ${ }^{35} \mathrm{~S}$ having an initial specific activity of about $0 \cdot 18 \mu \mathrm{c}$./unit was prepared by C. J. Perret as described in the Appendix, and kept sealed in ampoules in $\mathrm{N}_{2}$ after freeze-drying. The penicillin was dissolved in $0.01 \mathrm{~m}$ buffer at $\mathrm{pH} \mathbf{7 \cdot 0}$, and its concentration determined by bio-assay, using two dilutions, each in octuplicate, against similar dilutions of a standard solution (cup-plate technique, giving an accuracy of $\pm 5 \%$ ). Analysis by paper strip chromatography showed that $90 \%$ of the ${ }^{35} \mathrm{~S}$ was in the penicillin molecule, and that most of the rest was in penicilloic acid probably formed after the penicillin solution had been added to the paper. Apart from penicilloic acid, non-penicillin S impurity in the material used for these experiments was almost certainly considerably less than $5 \%$.

The solution of benzylpenicillin was kept frozen at $-10^{\circ}$, and, if needed again more than 7 days later, was re-assayed immediately before use. Loss of activity at $-10^{\circ}$ was very slight and did not amount to more than $10 \%$ in 7 days. Radioactive penicilloic acid was prepared enzymically by incubating equal volumes of a solution of radio-penicillin at $100 \mathrm{units} / \mathrm{ml}$. and cell-free penicillinase (activity: $5000 \mu \mathrm{l}$. $\mathrm{CO}_{2} / \mathrm{ml} . / \mathrm{hr}$.) for $60 \mathrm{~min}$. at $35^{\circ}$ immediately before use.

Assay of penicillin sulphur fixed on the cells after radio-penicillin treatment for $1 \mathrm{hr}$. at $0^{\circ}$, washing and freeze-drying on polythene disks, was done on a Geiger counter using the technique described by Pollock \& Perret (1951). The only modification found necessary was the addition of one standard drop of $3 \%$ gelatin to the spore suspension on the disk, followed by thorough mixing before freezing in order to prevent the fine dust of spores scattering off the disk while drying. This amounted to the addition of $0.66 \mathrm{mg}$. of gelatin to each disk and was allowed for in the final calculation. Vegetative 
cells became sufficiently glutinous on freeze-drying not to need such treatment.

Disintegration of cells. (a) Vegetative cells were disrupted by $10 \mathrm{~min}$. shaking with an approximately equal volume of glass ballotini on a Mickle vibrator, using a small quantity of Silicone DC Antifoam A. This caused almost complete disintegration of the cells.

(b) Spores were refractory to disruption on the Mickle vibrator or by treatment with ultra-sound. Fairly satisfactory, though not complete, breaking (see Pl. 1, fig. 7) was eventually achieved by three successive crushings at $-35^{\circ},-55^{\circ}$ and $-22^{\circ}$ with intervening thaws at $+2^{\circ}$ in the Hughes press (Hughes, 1951).

\section{RESULTS \\ Preliminary}

When suspensions of spores were treated with penicillin for $1 \mathrm{hr}$. at $0^{\circ}$ and subsequently washed free of penicillin and incubated (i.e. germinated and grown) for 2-3 hr. aerobically in $S$ broth containing $1 \%$ gelatin, no more penicillinase was formed than with untreated spores. This failure to adapt to pretreatment occurred whatever concentration of penicillin was used; and is

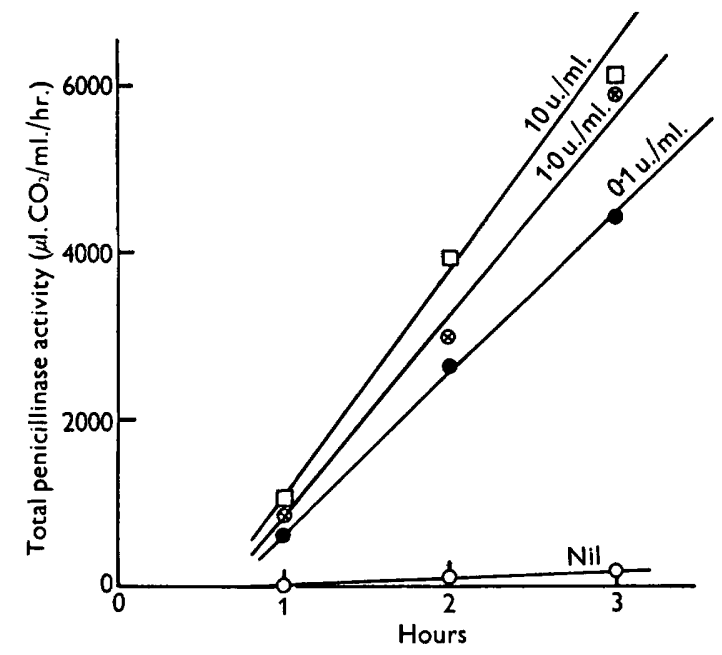

Fig. 1. Penicillinase production by germinating $B$. cereus spores $(2 \mathrm{mg} . / \mathrm{ml}$.) incubated aerobically at $35^{\circ}$ in $1 \%$ gelatin-broth containing $0,0 \cdot 1,1 \cdot 0$ and 10 units penicillin $/ \mathrm{ml}$.

in marked contrast to the behaviour of vegetative cells which react to such treatment by subsequently forming penicillinase at a rate up to 100 times that of untreated cells. However, when spores are incubated in the gelatin-broth medium in the presence of varying concentrations of penicillin, the cells adapt rapidly and, indeed, behave like vegetative cells do under such conditions (Fig. 1). There is thus nothing associated with the early stages of germination and growth which prevents cells showing the phenomenon of penicillinase adaptation. 
Moreover, when spores are pretreated with radioactive ${ }^{35} \mathrm{~S}$-labelled penicillin their $\mathrm{S}$ uptake is directly proportional to the concentration of penicillin used; and there is no disproportionately high uptake at low penicillin concentration as shown by vegetative cells (see Fig. 2). There is not, in fact, as with vegetative cells, any S uptake corresponding to the so-called 'specific' fixation of penicillin $\mathrm{S}$ suggesting a reaction between penicillin and some specific cell receptor which is saturated at a concentration of about $1.0 \mathrm{unit} / \mathrm{ml}$. (see Pollock \& Perret, 1951).

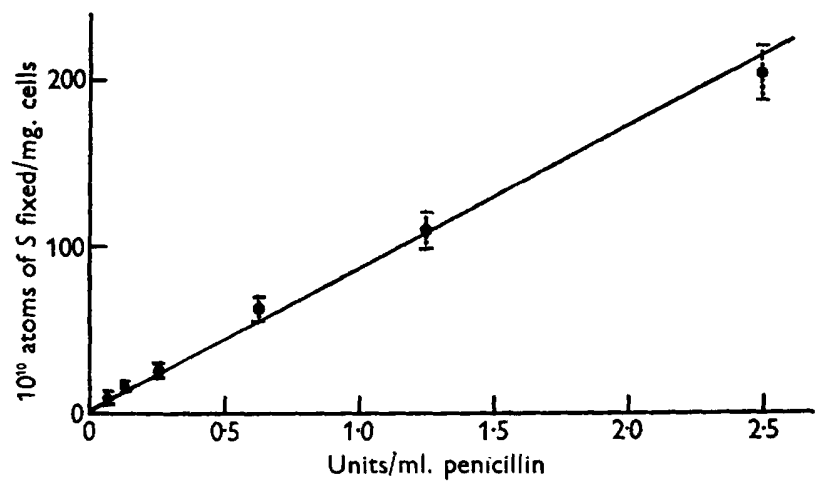

Fig. 2. Fixation of $S$ on $B$. cereus spores following treatment at $0^{\circ}$ for $1 \mathrm{hr}$. with different concentrations of ${ }^{35} \mathrm{~S}$-labelled penicillin, and subsequent washing. Limits of counting error shown for $\boldsymbol{P}=\mathbf{0} \cdot 05$.

There are two possible explanations for this difference: either (1) spores do not possess a specific receptor for penicillin $S$, or (2) spores are impermeable to penicillin. The latter alternative could, perhaps, be described more accurately as the hypothesis of there being some sort of a barrier preventing access of penicillin to the receptor-without any preconception of what sort of barrier it might be or where it functions.

\section{Production of 'adapted' spores}

If the impermeability hypothesis is correct, clearly it might be possible to produce adapted spores by allowing the penicillin to penetrate the cell and reach the receptor before the spores were fully mature. 'Then, if in fact some of the receptor substance were incorporated within the spore as they were being formed, such spores might be expected to form penicillinase at an increased rate when subsequently allowed to germinate and grow in a penicillin-free medium. This was indeed found to be the case. Fig. 3 shows the result of an experiment in which cells were treated in four different ways as follows:

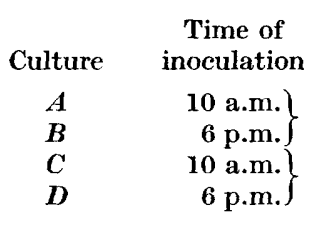

\footnotetext{
Subsequent treatment Nil

Addition of 100 units penicillin $/ \mathrm{ml}$. every $60 \mathrm{~min}$. for $8 \mathrm{hr}$. on the following day from 10 a.m. to 6 p.m.
} 
Four $100 \mathrm{ml}$. lots of medium were inoculated with one drop of a $10^{-6}$ dilution of standard spore suspension, two flasks at 10.0 a.m. and two at 6.0 p.m. and then incubated on the shaker at $35^{\circ}$. The onset of sporulation occurs consistently 16-18 hr. after adding an inoculum of this size, and, once begun, is complete (i.e. at least $95 \%$ of cells have produced spores) in 7-8 hr. Thus at 10 a.m. the following morning sporulation was complete in $A$ and $C$ and just about to begin in $B$ and $D$. The whole process of sporulation is

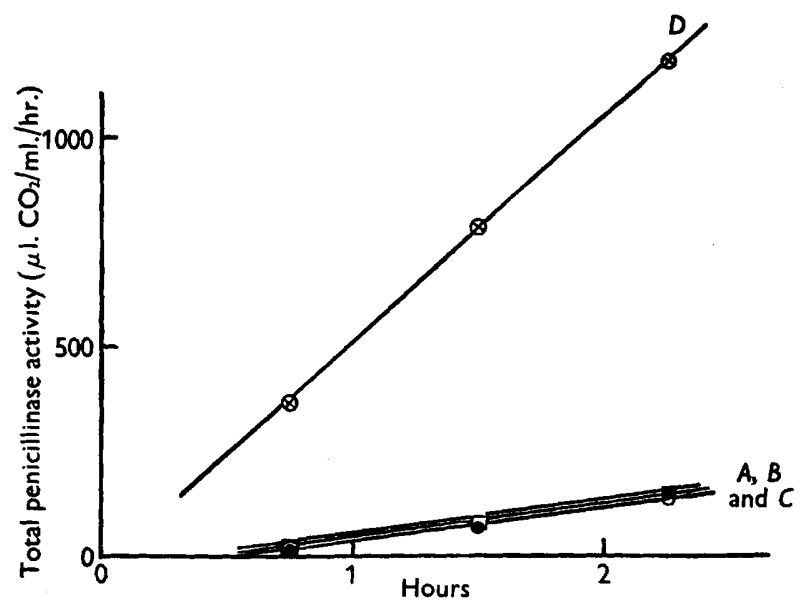

Fig. 3. Penicillinase production by germinating $B$. cereus spores 'primed' by penicillintreatment during sporulation $(D)$, compared with spores treated with penicillin after sporulation $(C)$ and with untreated spores ( $A$ and $B$ ), see text. Medium: $1 \%$ gelatinbroth. Aerobic incubation at $\mathbf{3 5}^{\circ}$.

illustrated in Pl. 1, figs. 1-6. The continuous $8 \mathrm{hr}$. penicillin treatment was thus applied to fully formed spores in $C$ and to cells during sporulation in $D$; $A$ and $B$ acting as untreated controls. Films of $B$ and $D$, which were made during this period, showed no detectable difference in the speeds and extent of sporulation, confirming that the repeated addition of penicillin had no effect on the process. All cultures were then left shaking at $35^{\circ}$ for a further $16 \mathrm{hr}$. (i.e. until $10.0 \mathrm{a} . \mathrm{m}$. on the $3 \mathrm{rd}$ day) to allow lysis of remains of vegetative cells. Spore suspensions were then prepared, from each culture separately, by heating at $60^{\circ}$ and thorough washing as described; and rates of penicillinase formation in $1 \%$ gelatin $+S$ broth followed. Fig. 3 shows that in $D$ (cells treated with penicillin during sporulation) there was an approximately tenfold increase in the rate of enzyme formation; while $C$ showed no significant difference from the untreated $A$ and $B$. 'Adapted' spores could also be prepared from cultures treated with a single dose of 100 units penicillin $/ \mathrm{ml}$. just before the onset of sporulation.

It should also be pointed out that: $(a)$ penicillinase activity was not detectable in any of the four spore suspensions before germination and growth in the broth; the term 'adapted' when applied to such cells is therefore perhaps misleading and might best be substituted by 'penicillin-primed'; 
(b) there was no significant change in the opacities of any of the four spore suspensions during germination and growth in broth for the $2 \frac{1}{2} \mathrm{hr}$. the experiment lasted. Observations by phase-contrast illumination showed, however, that most of the cells had germinated and were beginning to divide. When incubation was prolonged, increase in opacities occurred, but to the same extent in all cultures. There were no observed differences between the suspensions apart from their ability to form penicillinase.

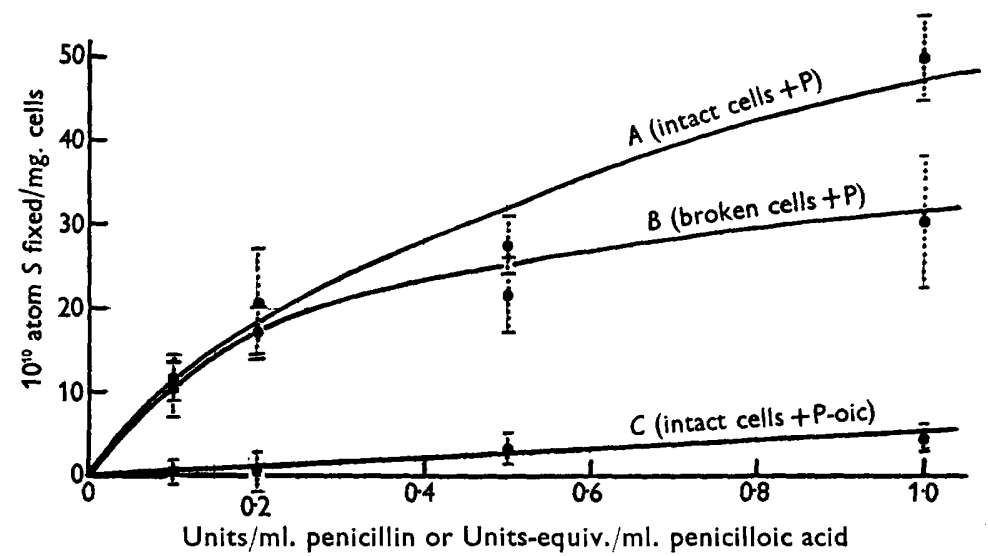

Fig. 4. Fixation of $S$ on $B$. cereus vegetative cells after treatment for 1 hr. at $0^{\circ}$ with different concentrations of ${ }^{35} \mathrm{~S}$-labelled penicillin or penicilloic acid followed by washing. $A$, intact cells; $B$, broken cells; $C$, intact cells after similar treatment with penicilloic acid prepared by enzymic hydrolysis of ${ }^{35} \mathrm{~S}$-labelled penicillin. Limits of counting error shown for $P=0 \cdot 05$.

\section{Penicillin sulphur fixation by crushed spores}

It was thought possible that if the inability of spores to fix penicillin $S$ specifically at low concentration were due only to an impenetrable barrier in the spore wall, then it might be possible to demonstrate such fixation after disrupting the spores mechanically. This should be feasible as long as the penicillin-binding receptor substance was not completely soluble and thus not removed during washing of the broken spores after pretreatment with penicillin. Few, Cooper \& Rowley (1952) reported that, with penicillintreated staphylococci, the penicillin was fixed largely on that portion of the cell which remained as the insoluble centrifugable deposit after cell disintegration. A preliminary experiment with $B$. cereus in which the solid debris after disruption of vegetative cells was treated with low concentrations of radioactive penicillin by the usual technique, showed the penicillin $\mathrm{S}$ to be specifically fixed by this material to about the same extent as by intact cells (Fig. 4). It seemed therefore reasonable to assume that mechanical disintegration of cells did not chemically or physically alter the properties of the cell material enough to cause any change in the ability to fix the penicillin S.

A suspension of spores was then crushed in the Hughes press. It differed from an intact spore suspension in its tendency to clump and was difficult to homogenize. When examined under the microscope a large proportion of 
spores $(30-40 \%)$ appeared unaltered and were clumped together with other cells of ill-defined outline and with amorphous solid debris. Pl. 1, fig. 7, shows the appearance of the spore suspension after crushing. Although many intact cells remain, a number of empty burst spore cases and amorphous granular material are easily visible. The crushed spores were kept at $0^{\circ}$ or below until just before use. They were then standardized to a concentration of $20 \mathrm{mg} . / \mathrm{ml}$. by weighing samples, and treated at a concentration of $2 \mathrm{mg} . / \mathrm{ml}$. with varying concentrations of ${ }^{35} \mathrm{~S}$-labelled penicillin for $1 \mathrm{hr}$. at $0^{\circ}$ in parallel with similar

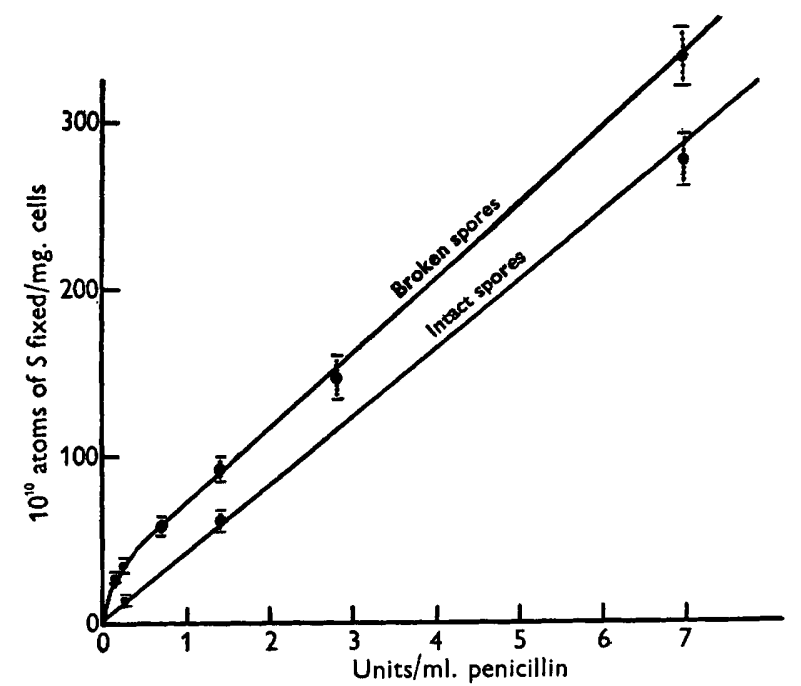

Fig. 5. Comparison of $S$ fixation on intact and broken $B$. cereus spores after treatment for $1 \mathrm{hr}$. at $0^{\circ}$ with different concentrations of ${ }^{35} \mathrm{~S}$-labelled penicillin, and subsequent washing. Limits of counting error shown for $P=0 \cdot 05$.

concentrations of intact spores from the same original batch. After three washings, during which a considerable fraction of soluble material was removed from the crushed spores in the supernatant fluid after centrifugation, the amount of S fixed was estimated (Fig. 5). Although there is no great difference between the two preparations in the total $S$ fixed at the higher levels of penicillin treatment, the divergence below a concentration of $1.0 \mathrm{unit} / \mathrm{ml}$. is marked. While the fixation by intact spores is more or less proportional to the penicillin concentration over the whole range tested, there is a disproportionally high uptake by crushed spores at the lower penicillin concentrations and, apart from a higher 'non-specific' fixation, the curve is very similar to that shown by vegetative cells.

\section{DISCUSSION}

It seems reasonable to conclude from these experiments that spores contain a receptor for specific fixation of penicillin $S$ and that their inability to react to treatment with penicillin-either in the form of adaptation to penicillinase production or by specific fixation of penicillin S-is due to the impermeability of the spore wall to penicillin. The mechanism of sporulation and the fact that 
'penicillin-primed' spores can be formed after penicillin-treatment of vegetative cells also suggest that the specific induction of penicillinase formation occurs inside the vegetative cell. Pl. 1, figs. 1-6, show how the spore appears to be formed by an inclusion of part of the vegetative cell not involving the cell wall. Knaysi (1946) has clearly shown that endospore formation in $B$. cereus occurs entirely within the cell wall; and in the case described here it is not easy to see how material on the outside of the cell could be incorporated into the spore. Previous work (Pollock \& Perret, 1951) has shown fairly conclusively that the receptor which specifically fixes penicillin $\mathbf{S}$ is the same as that which reacts to penicillin treatment by promoting penicillinase production. It is obviously simpler to assume that this receptor-substance is within the cell and is incorporated into the spore during sporulation, than to postulate some transmission of specific inducing power from this substance (if situated on the cell surface) through the cell wall and into the cytoplasm.

Reasons have previously been given (Pollock \& Perret, 1951) for believing that the curve of penicillin $S$ fixation shown by vegetative cells represents the combined effect of two different types of reaction: $(a)$ 'specific' fixation of $\mathrm{S}$ on a specific cell receptor which is saturated at about $1 \mathrm{unit} / \mathrm{ml}$. plus (b) 'non-specific' fixation on some cell material which adsorbs the $\mathrm{S}$ to an extent strictly proportional to the concentration of penicillin employed-at least up to 14 units $/ \mathrm{ml}$. This interpretation of two separate types of penicillin $S$ fixation is supported by the present results which show that with spores the non-specific type of fixation can be transformed into the non-specific + specific type simply by rupturing the cell wall.

It seems possible that 'non-specific' fixation of penicillin $S$ shown by spores represents that proportion which is absorbed on the outside of the cells. If so, it is likely that the same would apply to the non-specific fraction of $\mathbf{S}$ fixation from penicillin by vegetative cells. The higher value shown by spores ( 5 to $8 \times 10^{11}$ atoms S/mg./unit penicillin $/ \mathrm{ml}$.- -see Figs. 2 and 5) compared with that of vegetative cells $\left(2.5\right.$ to $3.0 \times 10^{11}$ atoms $\mathrm{S} / \mathrm{mg}$./unit penicillin/ml.—see Pollock \& Perret, 1951) is in keeping with the much greater total surface area/weight ratio of spore suspensions. The only alternative interpretation, in fact, is that it does not represent fixation of $S$ from penicillin at all, but from some non-penicillin $S$ impurity present in the penicillin solution. An $S$ impurity of less than $\mathbf{0 . 2} \%$ would be enough to account for the amount so absorbed. This, however, is rather unlikely, because in the case of vegetative cells the amount of $\mathrm{S}$ fixed from an enzymically produced penicilloic acid preparation (which would contain the same $\mathbf{S}$ impurities as the penicillin solution from which it was formed) was found to be only 20-25\% (see Fig. 4) of the average amount of 'non-specific' $S$ absorbed from penicillin. This hypothesis has little bearing on the problem of spore adaptation, but if true would be a simple explanation of the rather complex curve of penicillin $S$ fixation by vegetative cells. This latter could then be regarded as being composed of a specific fraction absorbed by the specific receptor within the cell plus a non-specific fraction absorbed purely on the cell surface. 
In this connexion it should be mentioned, in parenthesis, that much greater and very variable $S$ fixation was found in cells treated with penicilloic acid formed from penicillin by alkaline hydrolysis as compared with enzymically produced penicilloic acid. The results reported previously (Pollock \& Perret, 1951) regarding fixation of penicilloic acid $S$ are therefore inaccurate and misleading since there is little doubt that most of what was regarded as penicilloic acid $S$ was a $S$ impurity produced, although in very small quantities, by the alkaline treatment of penicillin. Enzymic hydrolysis of penicillin is specific and less drastic than alkaline hydrolysis, and therefore much less likely to cause increase in impurity. However, even with the 'enzymic' preparation it is quite possible that the $\mathbf{S}$ fixed is not derived from penicilloic acid itself but represents some trace of impurity present in the original penicillin solution. In any case, the low amount of $S$ fixed from penicilloic acid serves only to emphasize the highly specific uptake from penicillin at low concentrations.

I am much indebted to Dr D. E. Hughes for undertaking the crushing of B. cereus spores in his press and for the electron micrograph of crushed spores (Pl. 1, fig. 7). I also wish to thank Mr M. R. Young for taking the photographs of the stages of sporulation, and Miss Daphne Towler for technical assistance.

\section{REFERENCES}

Hughes, D. E. (1951). A press for disrupting bacteria and other micro-organisms. Brit. J. exp. Path. 32, 97.

Few, A. V., Cooper, R. D. \& Rowley, D. (1952). Reaction of penicillin with the staphylococcal cell wall. Nature, Lond. 169, 283.

Pollock, M. R. (1950). Penicillinase adaptation in B. cereus: adaptive enzyme formation in the absence of free substrate. Brit. J. exp. Path. 31, 739.

Pollock, M. R. \& Perret, C. J. (1951). The relation between fixation of penicillin sulphur and penicillinase adaptation in B. cereus. Brit. J. exp. Path. 32, 387.

KNAYSI, G. (1946). On the process of sporulation in a strain of Bacillus cereus. $J$. Bact. 51, 187.

\section{EXPLANATION OF PLATE}

Figs. 1-6. Sporulation in $B$. cereus during aerobic incubation at $35^{\circ}$ in ' $S$ ' broth after inoculation with 1 drop of $10^{-6}$ dilution of standard spore suspension (see Methods). Phase contrast illumination. $\times 1440$.

Fig. 1. $3 \mathrm{hr}$. Cells in 'log-phase' showing remains of spore-casings (from spore inoculum).

Fig. 2. $16 \mathrm{hr}$. Intracellular inclusion bodies (not present in cells during the log-phase) evenly distributed.

Fig. 3. $19 \mathrm{hr}$. Polarization of inclusion bodies to one end of cell. Some 'forespores' visible.

Fig. 4. $20 \mathrm{hr}$. Numerous 'forespores' and a few nearly mature spores.

Fig. 5. $23 \mathrm{hr}$. Mature spores present in most cells.

Fig. 6. $40 \mathrm{hr}$. Free spores after heating at $60^{\circ}$ for $1 \mathrm{hr}$. and washing.

Fig. 7. Electron micrograph of spores after crushing in the Hughes press; showing empty spore cases, amorphous debris and some apparently intact spores. $\times 4000$. 
Journal of General Microbiology, Vol. 8, No. 1
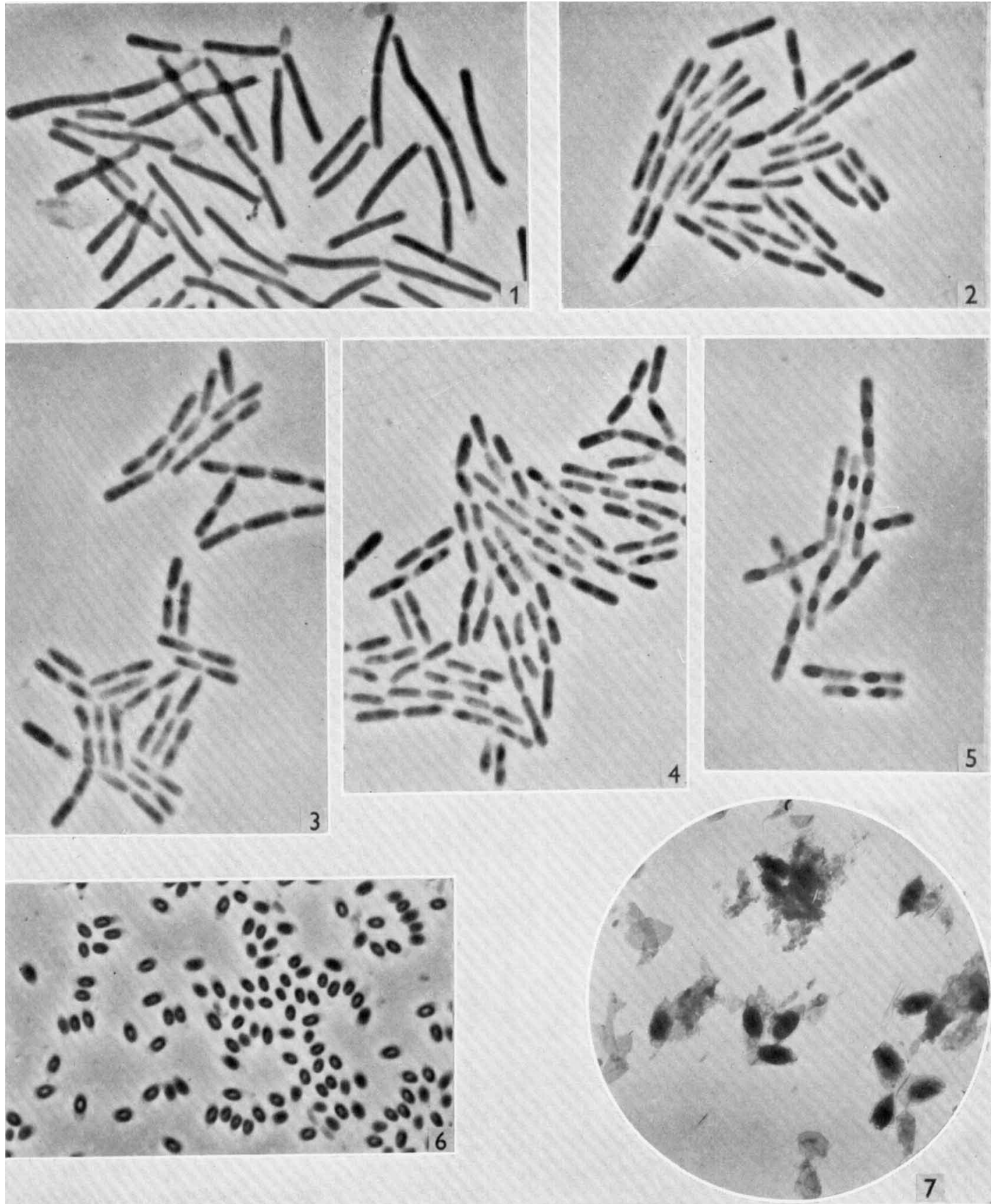

M. R. Pollock-Penicillinasl: adaptation in spores. Plate 1 